\title{
COVID-19 in Latin America: a first glance to the mortality
}

\section{Mortalidad por COVID-19 en América Latina}

\author{
Nubia Muñoz1 nubia.munoz@free.fr \\ Emeritus Professor at the National Cancer Institute of Colombia, and Former Unit Chief at the \\ International Agency for Research on Cancer, Lyon, France, International Agency for Research \\ on Cancer, Lyon, France
}

\section{OPEN ACCESS}

Citation: Muñoz N. Colomb Med (Cali). 2020; 51(2):e-4366. http://doi. org/10.25100/cm.v51i2.4366

Received : 02 Apr 2020

Revised : 25 Apr 2020

Accepted : 04 May 2020

Published: 11 May 2020

\section{Keywords:}

COVID19, andemics, Quarantine, Latin America, Spain, Belgium, Brazil, Quality Indicators, Health Care, Sweden, Colombia, SARS Virus, Risk Factors, severe acute respiratory syndrome coronavirus 2 .

\section{Palabras vlave:}

COVID- 19 , Pandemias, Cuarentena, America latina, Indicadores de calidad, atención médica, Colombia, Virus del SARS, Factores de riesgo, síndrome respiratorio agudo severo coronavirus 2, Brasil, Bélgica, España, Suecia.

Copyright: (C) 2020. Universidad del Valle.

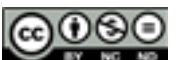

It is too early to know which will be the final death toll from the Covid-19 or SARS-CoV-2 virus epidemy in Latin America since the epidemy is still active and we will not know when it will end. The curve for new infections and deaths has not reached yet a peak (Figure 1). In addition, we know little about the epidemiology of this new virus.

The daily litany of the number of people infected with the number of admissions to hospitals and intensive care units and the number of deaths guides health authorities to plan health services and politicians to gauge the degree of confinement necessary to control the transmission of the virus, but it says little about the magnitude of the problem if we do not relate it to the population at risk. At the end of the pandemic, we will be able to estimate agestandardized death rates for the different countries, but until then the crude death rates will provide a first glance or snapshot of the death toll and impact of the pandemic from March to May 2020. Table 1 summarizing the crude mortality rates per 100,000 inhabitants in 15 Latin American countries, and shows that the virus has attacked these countries with varying intensity. As of May 30, 2020, Ecuador, Brazil, and Peru have the highest mortality rates, followed by Panama, Mexico, Chile, and Bolivia, while Colombia, Argentina Cuba, Uruguay, Paraguay, and Costa Rica have the lowest.

These rates are well below those estimated in other countries in Europe and North America: Belgium (82.6), Spain (58.0), the United Kingdom (57.5), Italy (55.0), France (42.9), Sweden (41.4), and the US (30.7). (Johns Hopkins CSSE, May 30, 2020). However, in the European countries and the US the number of deaths has reached a peak, while this is not the case in Latin American countries. (Figure 1). It should be taken into account that the above rates are crude and therefore, some of the differences could be due to the fact that European countries have a larger proportion of the population over 70 years of age in whom higher mortality rates have been reported.

The WHO has alerted to the rapid increase of infections and deaths in Latin America in the coming months, especially in Brazil; the IHME (Institute for Health Metrics and Evaluation of the University of Washington estimates that by August 4, 2020, in Brazil 125.833 deaths will have occurred compared with 27.878 at May 30, and in Colombia, 4,359 deaths are estimated to have occurred by August 4, compared with 855 deaths in May 30.

The magnitude of these rates has revealed how weak and obsolete most health systems are; with a very few exceptions, no country was prepared to handle and control a health emergency 


\section{Conflict of Interest: \\ None}

\section{Acknowledgment:}

Special thanks to Dr. Luis E. Bravo who performed Figure 1

\section{Corresponding author:}

Nubia Muñoz. Emeritus Professor at the National Cancer Institute of Colombia, and Former Unit Chief at the International Agency for Research on Cancer, Lyon, France, International Agency for Research on Cancer, Lyon, France, e-mail: nubia.munoz@free.fr
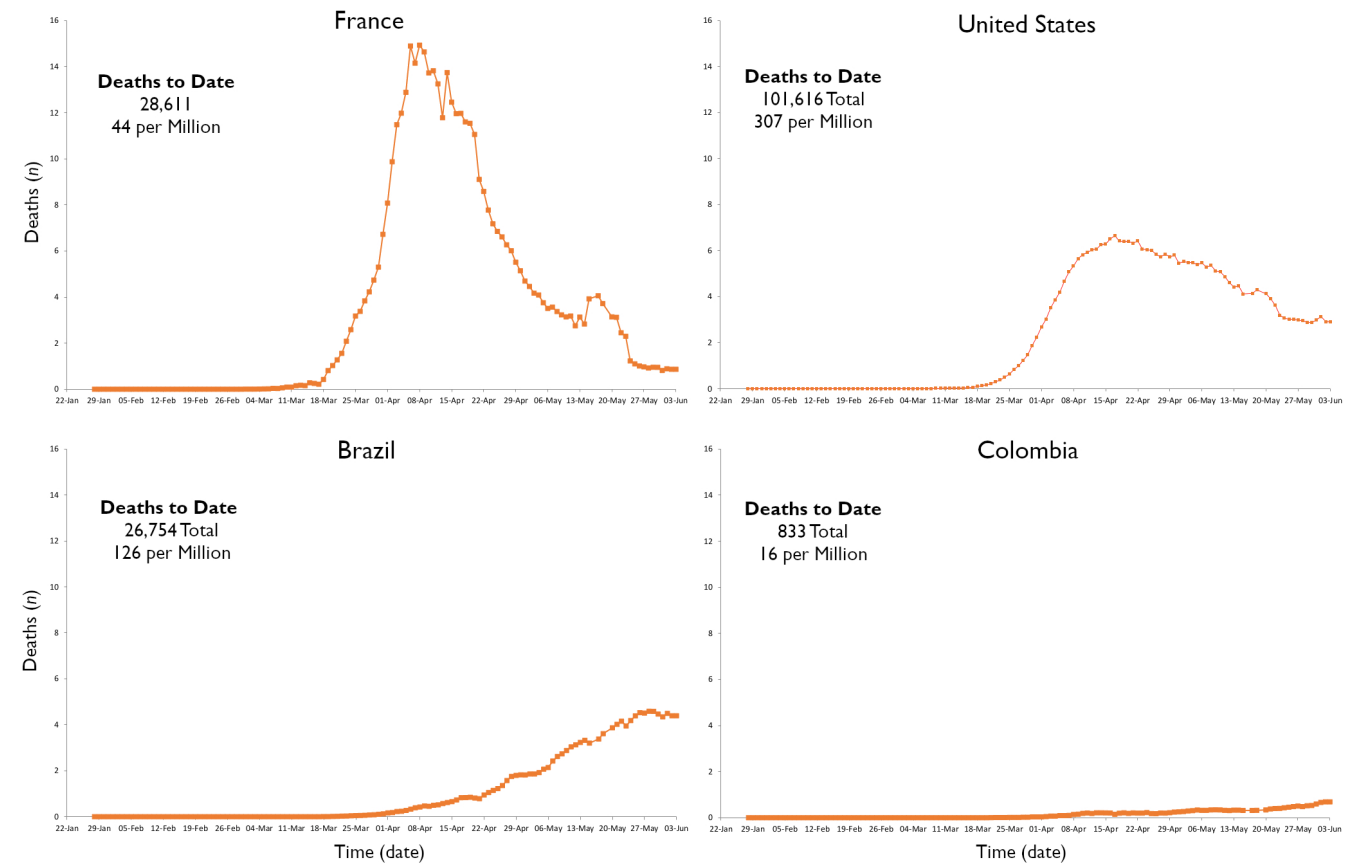

Figure 1. Daily COVID-19 Death tolls for selected countries per million, 7-day rolling average: may 27 update. Source: Johns Hopkins COVID-19 dataset as of May 27

of the magnitude of the current pandemic. It has also revealed the high degree of technological dependence of the vast majority of countries mainly from China, the world great workshop. The absence of an effective treatment and of a prophylactic vaccine and the ineffectiveness of the health systems led most countries to implement a medieval measure, the confinement or quarantine of the population, to decrease the transmission of the virus and thus avoid the collapse of the health systems.

Our main hope for a return to normal life lies primarily in the development of an effective and safe vaccine. As of May 30, 2020, there were 131 vaccine projects worldwide, 121 in the preclinical evaluation, and 10 in clinical evaluation in humans. Two of the projects in the preclinical phase are in Latin America (Fundação Oswaldo Cruz \& Instituto Buntantan, and Univ. Of Sao Paulo, Brazil). The speed of development of these vaccines has been extraordinary; What normally takes a decade has been done in a couple of months. In addition, to speed up its clinical evaluation, the WHO has designed and proposed to coordinate a large international randomized controlled clinical trial of the different vaccines. (WHO Draft landscape of COVID-19 candidate vaccines).

However, my experience with cervical cancer prevention shows that the problem is not solved by having an excellent vaccine if people do not have access to it, or do not want to use it. Colombia had one of the best immunization programs against the human papillomavirus (HPV) with coverage rates between 80 and $90 \%$, until the mismanagement of a massive psychogenic event in a small city in northern Colombia linked to rumors and false news, reduced coverage to less than $10 \%$. Vaccine skepticism has spread to other countries and other vaccines, which has led the WHO to declare it as one of the 10 health priorities of the decade. Something similar can occur if a safe and effective vaccine to prevent Covid-19 is obtained. Surveys in the US, France, and Romania reveal that $25 \%$ to $33 \%$ of respondents would reject Covid-19 vaccination.

The impact of quarantine on the economy and on public health programs has been considerable. The WHO, Gavi, and UNICEF have recently warned of the great disruption that 
Table 1. Crude Mortality rates from Covid-19 in Latin American Countries

\begin{tabular}{lclc}
\hline Country & Mortality rate per 100,000 & Country & Mortality rate per 100,000 \\
\hline Ecuador & 19.5 & Colombia & 1.7 \\
Brazil & 13.3 & Argentina & 1.2 \\
Peru & 12.8 & Cuba & 0.7 \\
Panama & 7.8 & El Salvador & 0.7 \\
Mexico & 7.5 & Uruguay & 0.6 \\
Chile & 5.0 & Guatemala & 0.5 \\
Bolivia & 2.6 & Paraguay & 0.2 \\
& & Costa Rica & 0.2 \\
\hline
\end{tabular}

the pandemic is causing to the immunization programs of at least 68 countries, leaving some 80 million children under 1 year of age in the poorest countries at risk of dying from diseases like diphtheria, measles, and polio. Other programs that are also being severely affected include screening for cervical cancer.

The economic impact of quarantining is much greater on most middle and low-income countries, where a considerable proportion of people in the informal economy barely survive on precarious wages. This people are now suffering from hunger. In addition, the UN has estimated that over 300 million children who rely on school meals for most of their nutritional needs might now be at risk of acute hunger, which could reverse the progress made in the past 2-3 years in reducing infant mortality within a year.( United Nations Sustainable Development Group, April 15, 2020. United Nations Sustainable Development Group Policy brief: the impact of COVID-19 on children.https://unsdg.un.org/resources/policy-brief-impact-covid19-children).

On a positive note of the Covid-19 pandemic, we note that science has generally been at the basis of political decisions and that international cooperation in research has been strengthened. 